\title{
Frontiers and pioneers in (the study of) queer experiences in Africa Introduction
}

\author{
Rachel Spronk and S. N. Nyeck
}

This part issue of the journal Africa broadly explores the idea of frontiers and pioneers in the study of queer African lives. We envisage frontiers as exploring new openings in the study of sexuality by putting forward the practices and experiences of people across the African continent. We propose to study queerness as part of broader quotidian realities so as to further theorize the study of sexualities and queerness. We propose the term 'pioneer' for the interlocutors in our studies: (self-identifying) women, men and queerying persons who courageously explore contradictory paths in their various contexts. As such, we encourage an imaginative employment of queer as indicating a horizon of curiosity and imprecision. In making queerness not an object of study but rather a subject of its own theorization based on everyday experience, this special journal issue explicitly and deliberately asserts the vernacular and the mundane as a locus of knowledge. One implication is especially pertinent: knowledge on queerness cannot be prefabricated or preassembled in theoretical laboratories with the aim of merely applying it to an African context. By doing so, Africa functions - as it always has - only as a variable in the study of cultural difference, one that is different from, by implication, a Euro-American centre. 'Or, as is happening too often, queer African voices and experiences will be absorbed as "data" or "evidence," not as modes of theory or as challenges to the conceptual assumptions that drive queer studies' (Macharia 2016: 185). Foregrounding the mundane rather than the urbane (as in 'suave', for which queer theory has a strong penchant), we are not trying to 'define' African queer sexualities; rather, we seek to provoke conversations about the terms and agencies of their expansion through the prism of frontiers and pioneers.

Inspired by Francis Nyamnjoh's and Stella Nyanzi's work, we argue that studying the quotidian is a critical first step. Even as we follow up on an existing body of literature on queer sexualities in African societies, this literature shows how the investigation of the everyday is easily subsumed by other concerns; our aim is thus to centre people's practices and experiences as a focal axis of theorizing.

\footnotetext{
Rachel Spronk is Associate Professor in the Department of Anthropology at the University of Amsterdam. In her work on gender, sexuality and the middle classes she combines the ethnographic study of practices and self-perceptions with the task of rethinking our theoretical repertoires. Email: R.Spronk@uva.nl

S. N. Nyeck is a visiting scholar at the Vulnerability and Human Condition Initiative at Emory School of Law and a research associate with the Chair for Critical Studies in Higher Education Transformation (CriSHET), Mandela University. Email: sngonye1@g.ucla.edu

(C) The Author(s), 2021. Published by Cambridge University Press. This is an Open Access article, distributed under the terms of the Creative Commons Attribution-NonCommercial-ShareAlike licence (http://creativecommons.org/licenses/by-nc-sa/4.0/), which permits non-commercial re-use, distribution, and reproduction in any medium, provided the same Creative Commons licence is included and the original work is properly cited. The written permission of Cambridge University Press must be obtained for commercial re-use.
} 
We borrow Nyamnjoh's metaphor of frontier Africans to deal with a few lingering questions regarding the study of sexuality more broadly.

We directly respond to Nyanzi's call to calibrate the study of gender and sexuality as part and parcel of people's everyday lives rather than following the grid of a global LGBT+ discourse, which often endorses a taxonomic approach that labels people in terms of intrinsic psychic traits they are believed to possess (Nyanzi 2014). According to Nyanzi, erotic desires and gendered subjectivities can be grasped only by focusing on the breadth of people's lives and their interconnectedness:

[The] canvas of possibilities demanding queer production of knowledge from Africa includes relationships, pleasure, intimacy, parenthood, education, voice and expression, representation and visibility, housing and shelter, movement, migration, exile and asylum, employment, income generation, livelihoods, family, ritual, health, spirituality, religion, faith, violence, security and safety, nationalism, ethnicity, and globalization. (Nyanzi 2014: 63)

As Nyanzi states, reflecting on her own experiences, queerness cannot be neatly defined because same-sex and cross-sex desires and lives are intimately connected. We take up Nyanzi's suggestion to move away from studying sexuality as forming the core of one's self or one's identity and, instead, study the ways in which people play into the inherent instability of normative structures. Moreover, she invites scholars of queer sexualities to analyse normative discourse not only as descriptive, as if they illustrate actual praxis, but also always in relation to what they represent or speak for. For instance, as Gaudio and Pierce rightly observe, the virulent homophobic discourse that swept over Nigeria in the 2010s cannot be explained only by the presence of people with same-sex proclivities, cultural reasons and/or religious change, but that longer-standing moral anxiety and political conflict are important in explaining the surge (Gaudio 2014; Pierce 2016). How, then, to theorize from people's everyday realities, desires and practices as they navigate, confirm and simultaneously defy normative expectations? How to include in our definitions and explorations of queerness the vagaries of people's daily realities in the hetero-patriarchal structures of their society? How to study both resilience and vulnerability in situ?

In a similar vein to Nyanzi's argument, Nyamnjoh contends that African realities are not steeped in dualisms, binaries, dichotomies and essences as postulated by 'Western epistemologies that tend to privilege neat dichotomies and dualisms' (2017: 255). Instead, he argues for the recognition of the incompleteness of life and for embracing its potentialities rather than seeing it as a lack that needs to be amended. As incompleteness is the normal order of things (not only in Africa, of course), people's capacity to straddle physical and cultural boundaries pays attention to the enabling conditions and ambiguous realities of a world that is always in flux. The messiness of everyday life engenders being and becoming not as a singular linear process but as a manoeuvring practice. Central to his argument is also the way in which conviviality recognizes and celebrates incompleteness as a tool for activating human capacity to manage social transformation. Similarly, Nyanzi's insistence on studying sexuality as it emerges from people's daily vagaries and fortunes implies the need to incorporate incompleteness but also sociality and relatedness in our theoretical repertoires. In her summary 'of 
life', pleasure, parenthood, health, faith and security build onto each another so as to capture the interconnectedness of erotic desire and sexual practices with everyday aspirations. For Nyamnjoh and Nyanzi, African histories have led to contemporary realities in which people often have a special talent for producing open forms of knowledge. And it is exactly this we aim to foreground as a new avenue in theorizing sexuality.

What we are proposing is not entirely novel, as the small but significant body of literature on (queer) sexualities has been advancing a promising research programme. Apart from the many articles and book chapters, a few edited volumes testify to this budding research area. From the first collection on 'African homosexualities' in 1998 (Murray and Roscoe) via the collection of female same-sex biographies (Morgan and Wieringa 2005) to the birth of two queer readers (Ekine and Abbas 2013; Nyeck 2019), questions of visibility, identity, justice, politics and much more have been deliberated upon from interdisciplinary perspectives. The Queer African Reader brings together academic writings, political analyses, life testimonies, conversations and artistic works to 'explore issues of identity, resistance, solidarity, pinkwashing, global politics, intersections of struggle, religion and culture, community, sex, and love' (Ekine and Abbas 2013: 3). Nyeck and Epprecht also provide a spectrum of studies to 'unravel silences and stereotypes about Africa as a place [of] highly restrictive and oppressive ideologies of heterosexual masculinity and femininity' (2013: 3). Matebeni and Mbsisi, in a special issue on the importance of language, also warn against the hegemony of global discourse, as Nyanzi does, but they also point out how '[d]iscomforts [with global discourse], public health discourses and critiques of identity categories have contributed towards a growing vocabulary of terms about sexual and gender diversities' (2015: 3). Apart from a few texts, many of these works deal more with the politics of queer sexualities and with the discourse on queer sexualities. In this part issue we wish to focus on queer experiences and use them to reflect back on the ongoing debate about queer sexualities.

In fact, African contemporary realities suggest innovative analytical directions of global heuristic value for gender and sexuality studies. Even in the West, 'sexuality' has started to break down under its own conceptual weight (cf. Halberstam 2012), but scholars in and from Africa have long recognized its limitations as an analytical frame to understand various sexual and gendered subject positions. ${ }^{1}$ The ethnographic studies we mention and rely on here have compiled significant analyses on the questions of orientational sexuality; erotic practice and people's self-perceptions; how the relationship between body, gender and desire is understood by people themselves, as well as conceived of by others such as scholars; and many more. Yet, rather than outlining how ethnographic inquiry is differently organized in Africa compared with elsewhere, these realities can be used to reflect on theorizations of queer sexualities. In Douglas Clarke's words: 'Africa has a model for queer theory that is largely unexplored in the Western world' (2013: 175). The direction of this part issue is therefore to study (global) 'sexualities

\footnotetext{
${ }^{1}$ See the following books: Dankwa (2021); Ekine and Abbas (2013); Epprecht (2008); Gaudio (2011); Matebeni (2014); Mohammed et al. (2018); Morgan and Wieringa (2005); Murray and Roscoe (1998); Nyeck (2019); Nyeck and Epprecht (2013); Reid (2013); Tamale (2011).
} 
from Africa (rather than sexualities in Africa) - a deceptively small lexicological difference that reflects a much broader epistemological and political stance' (Hendriks and Spronk 2020: 6).

Keguro Macharia (2016) offers a powerful and poetic exemplar of the dilemmas of writing from Africa and as a queer African scholar. With him, we query how to enter a conversation about queerness with the full knowledge that such an undertaking may live behind a paywall and therefore remain inaccessible to many in Africa. But, he asks, how does one 'unlearn the fluencies that so readily grant access to conversations in mainstream queer studies?' (ibid.: 183). How to undo some of the urbaneness (suaveness) that dominates much of queer theory? Beginning to answer these questions entails more than just keeping a critical distance from the Euro-American queer canon. It requires the deconstruction of queer scholarship as we know it by advancing perspectives that are accountable to lives in Africa as producers of knowledge in practice and theory.

Both Nyanzi's and Nyamnjoh's invocations of the incompleteness of life are very powerful tools for exploring new epistemological avenues. Life in African societies (as elsewhere) is not as firmly structured as moral discourse would have it. And it is precisely the pervasiveness of life's imperfectness that provides potentialities, as people find ways to pounce on possibilities and manipulate social expectations. The first-hand narratives of queer Nigerian women in the anthology She Called Me Woman (Mohammed et al. 2018), for instance, are exceptional in showing the breadth and variety of queer lives in one single country. From women living in precarious and/or fearful circumstances to women living their queer lives with the audacity of youth; from women well versed in global queer discourse to women advancing vernacular ways of queer lives; and from women supported and loved by their networks to women hiding parts of their lives - all these narratives articulate how life can never be simply assumed. This process of negotiating incompleteness is not, however, without its frictions, paradoxes and conflicts. Diekara Oloruntoba-Oju in this issue persuasively considers the vicissitudes that characterize life itself. As S. N. Nyeck argues, such frictions are productive because '[t]he idea of queerness must remain paradoxical in Africa in order to safeguard its critical nature and ability to puzzle' (Nyeck 2011: 195).

One of the major challenges for the theorization of sexuality is its relation to domination and particularly to the hetero-patriarchal structures against and through which queer lives unfold. Rather than looking for ways to distinguish domination from resistance, we propose to embrace their interconnectedness. Approaching people's lives in the way Nyanzi invites us to do indeed incorporates how people simultaneously confirm and defy gendered and sexual regimes. Bringing into view the lived paradoxes of the ways in which gender, body and desire intersect beyond a binary of domination vis-à-vis resistance, we provide new avenues of theoretical and political interest. Yet there is no one particular way of being that can be hailed as a kind of 'queer apotheosis' in Africa. For instance, in today's Nairobi, a variety of realities come together: while a small but confident queer or LGBT+ community is maturing, a small number of households headed by two men and raising families existed long before something called a 'queer' or 'LGBT+' community came into being. Interestingly, such households live their lives outside the organized queer networks (and sometimes even resist them) and coexist with a relatively virulent homophobia in the 
public sphere. ${ }^{2}$ Similarly, William Banks and Serena Dankwa's work on men and women in Ghana who engage in same-sex erotic practices explores how their sexual subjectivity collides with social norms but also how, at the same time, these heteronormative norms are important to the self-understandings of these men and women, especially when the issue of pursuing relationships emerges. Heteronormativity is thus central to their self-perceptions and - unless one intends to qualify these men and women as suffering from false consciousness not something that needs to be undone or automatically fought against (Banks 2011; Dankwa 2011). It is therefore high time to embrace the existence of such diversities and seeming contradictions (cf. Pierce 2016). To use Nyamnjoh's vocabulary, such research shows how people are often 'pioneers' in their social worlds, as they bend possibilities and confront normativities. In so doing, they become 'frontier' agents who can provide new directions to scholars interested in the study of queer lives in Africa - on the condition that we see people as their own, and our, theoreticians.

If we thus take the vicissitudes and the dictionary terms and meanings of everyday life as a starting point, where does that leave us regarding our analytical terms? Hendriks (2018) argues that we need to overcome the ontological alterity that permeates scholarship and divides 'us' (the researchers) from 'them' (the objects of research), not by trying to 'represent' voices, people or experiences, but by taking up these conceptions and experiences to radically unthink the premises that underlie taken-for-granted concepts and frameworks. Yet how can we do so when, as Neo Musangi eloquently asserts, 'I struggle to find a language and a form with/in which to speak of myself ... To have to settle for "a thing" is to engage the limits of language; the desperate search for a naming word, a noun' (2014: 53-4). Rather than advocating a new language or conceptual framework, we therefore propose to look at what is commonly called sexuality or sexualities as a process.

So far, we have used 'queer' while acknowledging that it is a contested term and concept, because of its Euro-American footing. While it goes beyond this introduction to delve into the important discussion concerning its contestedness (see Macharia 2016; Nyeck and Epprecht 2013: 3-5; van Klinken 2019: 7-10), we propose the following provisional solution. First, we use the term 'queer' to indicate a field of non-normative genders (as opposed to anti-normative; see Hendriks in this issue), desires and practices where same-sex and cross-sex desires and acts are not mutually exclusive. While Ekine and Abbas use a similar definition to explicitly denote a political frame (2013: 3), we mean to use it in a more literal way: to refer to unexpected, strange or defiant desires and practices - their possibilities as well as their burdens. Second, rather than focusing on queer as a set of predefined gender characteristics, modes of behaviour or orientations of desire, we suggest twisting the term 'queer' by combining it with the verb 'to query': queerying. ${ }^{3}$ Unlike the corresponding noun, queerying implies inquiry, curiosity and

\footnotetext{
${ }^{2}$ This is explored in research conducted by Rachel Spronk in 2001 and explored further in 2019 by Apostolos Andrikopoulos, to be published in the future. See also M'Baye (2013).

${ }^{3}$ Xavier Livermon also used the term 'queer(y)ing' in the title of the article 'Queer(y)ing freedom: black queer visibilities in postapartheid South Africa' (2012), but he does not explicitly theorize his choice. The phrase appears in literature more broadly, not explicitly outlining a new
} 
unfinishedness while its horizon is clear: the arena of non-normative desires and practices. As such, we endorse Matebeni and Pereira, who propose queer 'as an inquiry' (2014: 8).

Queerying lives defy hetero-patriarchal structures and expectations; they may sometimes be subjugated by the latter but even then they articulate only the instability of normative regimes. There is a need to question the dualistic assumptions that mark both public debates and scholarship about sexuality. In particular, there is a need to go beyond the binary oppositions of suppression versus resistance, freedom versus conformity, but also aspects such as identity versus ignorance (the idea that closeted people have not yet found their true self), the way in which the connection between genitals and gender is often understood, and many more dualities that mark the field of sexuality research as much as people's view in the everyday (Spronk 2018; see also Geschiere 2017; Gunkel 2010; Reid 2013). Queerying what is permissible within and beyond gendered expectations and erotic probabilities also implies bridging the gap that traditionally exists between 'queer studies' and gender and sexuality studies. In this, Nyanzi's academic track record is exemplary, as it cannot be captured by one or the other. But also Sylvia Tamale's landmark reader African Sexualities (2011) testifies to this ethos of inclusivity. As editors, we therefore do not subscribe to notions that equate queerness with sexuality or desire in a narrow sense.

Nyanzi also points to another matter of importance: the dominance of anglophone perspectives in perceiving queer lives in both activism and scholarship (Nyanzi 2014; see also Matebeni 2014). In fact, she explicitly argues for a break with the anglophone acronym LGBT+. While this discourse is pervasive and while many, especially younger generations, find recognition in the idea that one's object of erotic desire defines what one 'is' (this does not apply to the ' $\mathrm{T}$ ' - transgender), for many others - those who do not speak English or do not have access to the internet, for example - it has little or no resonance with their lives. Inspired by Nyanzi's call for 'queering queer Africa', we propose to reject queerness as an end goal tied to outcomes that are standardized. Rather than circumventing the question of identity, we wish to situate it within the history of unequal encounters in a globalizing world where certain groups find recognition in movements based on identity politics while others do not. Thus, we hope to recognize the affordances and opportunities in environments that are usually dismissed as homophobic or closeted (cf. Dankwa 2021). In this way, we can pay attention to what Macharia calls the 'circulating indifference of conceptual frames to Africa's lived experience' (2016: 185) and definitively break away from hegemonic ways of understanding queer in identarian terms. ${ }^{4}$ As Oudenhuijsen analyses in this issue, it is important not to take people's usage of terms such as 'gay', 'lesbian' or 'queer' as self-evident but to queery how they appropriate them. People's lives are contradictory and complex, and rather than

\footnotetext{
direction of scholarly focus as we define here, but more playfully twisting terms. Also, queer as a verb rather than a noun has been invoked more often. However, apart from Livermon, scholars do not often raise this discussion in the study of sexuality in Africa.

${ }^{4}$ Of course, much queer theory is deeply suspicious of 'identity' and 'identity politics', which is why there was a need for queer studies in the first place as a response to go beyond gay and lesbian studies. We generalize here, of course, and highlight tendencies in scholarship and activism.
} 
seeing messiness as a hindrance, it can also be appreciated for its heuristic and exploratory breadth.

Our aim is not, however, to present queer lives as an endless field of possibilities. As, for instance, Human Rights Watch conscientiously documents, women and men who do not (always) walk the fine line of normative gender and sexual expectations are at risk in various African countries. ${ }^{5}$ The violence people risk varies in intensity and differs according to country or region. It also varies according to gender, age, class, religion, and much more. Paying attention to civil and human rights violations and fighting for social justice therefore remains pertinent. Yet, while this is a vitally important area of study, one should also acknowledge the partial nature of its production of knowledge on queer lives in Africa, which, for good reasons, remains heavily oriented towards violence and injustice and thus easily leaves out other aspects of what queer lives are also about. In this part issue, using the term 'queer' as a verb and/or as an adjective helps us explore themes and questions that open up perspectives that (re)centre inquiry around everyday practices as the loci of situated queer theorizing. Queerying, then, helps move the frontiers of the possibilities and impossibilities of defiant desires and unruly genders. And people from all walks of life can be pioneers in exploring the instability of hetero-patriarchal structures, as well as their queer affordances and repercussions.

There is, however, one group of pioneers on whom we wish to shed light namely, established scholars on the continent who are moving beyond specific boundaries and creating new frontiers beyond the usual ways of studying sexuality as a matter of health, human rights, sex education, and so on. Pioneering in this sense has the allure of venturing beyond familiar disciplines and axes of intervention and following roads less travelled in the study of sexuality in Africa. Sometimes this comes with serious repercussions, as we know of colleagues who were threatened with resignation if they published their work on female and male same-sex intimacies. Others, who might have considered queer research topics, found it safer to at least superficially remain within the delicate lines of what is seen as 'acceptable' research. It is also quite clear that, in many institutions, studying queer lives is simply overlooked. As we have learned in creating this issue, junior scholars working on queer subjects are in a precarious position: some work on a contractual and temporary basis and remain vulnerable because they are preoccupied with securing a permanent job. Those without a contract experience an even greater vulnerability and a real threat to employment. Yet, it is important and perhaps surprising to also point out how many MA theses and $\mathrm{PhD}$ dissertations on gender, erotic practice and sexual diversity are nonetheless completed at African universities. While there are myriad reasons why most of these young scholars do not have a career or why their work is not published, it is - as Akosua Adomako Ampofo points out - the obligation of every scholar to find this literature as part of her study.

Initially, we set out to make this part issue a conversation between scholars at different stages of their careers, with a preference for contributions by young

\footnotetext{
${ }^{5}$ See 'Human Rights Watch country profiles: sexual orientation and gender identity', 23 June 2017 <https://www.hrw.org/news/2017/06/23/human-rights-watch-country-profiles-sexual-orient ation-and-gender-identity>, accessed 10 February 2021.
} 
Africa-based researchers. But while we started our collaboration with eleven authors, no fewer than eight dropped out before the end of the process due to a lack of time because of their enormous workloads and/or because of their precarious institutional position. We cannot leave this unmentioned. Simply calling it a missed opportunity is an understatement: we are losing crucial knowledge and the result is the ongoing production of incomplete knowledge on sexualities in African societies, and particularly on female sexualities. African scholars are therefore not only pioneers; they are also at risk of not being able to develop their capacity to the full or to move the frontier of the study of sexuality.

As the mundane has a tendency to exceed language and methodologies, the focus on pioneering seeks to engage with the overflow of meaning in the (un)making and (un)learning of queer lives in context. The contributions by Diekara Oloruntoba-Oju, Loes Oudenhuijsen and Thomas Hendriks articulate exactly this. Oloruntoba-Oju queeries queer Africa in the spirit of NoViolet Bulawayo's book We Need New Names to understand the diversity and ambiguity of women's pioneering voices in the book She Called Me Woman. Oudenhuijsen directs our attention to same-sex desiring women in Senegal and how they embody the frontiers of queering scholarship from Africa as pioneering agents by showing how a religious notion such as sutura paradoxically provides space for queer lives. Hendriks takes yet another direction in queerying: his aim is to ethnographically undo the privileged theoretical position of 'queer' as anti-normative from the outset by showing how queer affordances of everyday life and its incomplete normativities in urban Congo call for another relationship between queerness and normativity. With these three articles, we hope to make a start in thinking with and through frontiers and pioneers in the ongoing study of queerying sexualities in and from Africa.

\section{Acknowledgements}

We wish to thank all the scholars who have been part of the collaboration out of which this issue evolved. We particularly wish to thank Thomas Hendriks and Peter Geschiere for their infallible guidance in rethinking sexualities and their support in writing this introduction. We have been engaging in longer-term discussions during conferences to deliberate how to carve out new ways of studying and writing about gender, sexuality and desire in African societies. We wish to thank the IAI for its generous financial contributions that enabled these conversations. Unfortunately, quite a few participants who have taken an interest in the project were unable to submit their work for this issue. Nevertheless, scholarship is thinking in progress and we trust that sooner or later all work will become available.

\section{References}

Banks, W. (2011) “"This thing is sweet”: ntetec and the reconfiguration of sexual subjectivity in post-colonial Ghana', Ghana Studies 14 (1): 265-90.

Clarke, D. (2013) 'Twice removed: African invisibility in Western queer theory' in S. Ekine and H. Abbas (eds), Queer African Reader. Oxford: Pambazuka Press. Dankwa, S. (2011) “The one who first says I love you”: same-sex love and female masculinity in postcolonial Ghana', Ghana Studies 14 (1): 223-64. 
Dankwa, S. (2021) Knowing Women: same-sex intimacy, gender and identity in postcolonial Ghana. Cambridge: Cambridge University Press.

Ekine, S. and H. Abbas (eds) (2013) Queer African Reader. Dakar and Oxford: Pambazuka Press.

Epprecht, M. (2008) Heterosexual Africa?: The history of an idea from the age of exploration to the age of AIDS. Athens OH: Ohio University Press.

Gaudio, R. P. (2011) Allah Made Us: sexual outlaws in an Islamic African city. Hoboken NJ: John Wiley \& Sons.

Gaudio, R. P. (2014) 'Dire straights in Nigeria', Transition: An International Review 114: 60-9.

Geschiere, P. (2017) 'A "vortex of identities": freemasonry, witchcraft, and postcolonial homophobia', African Studies Review 60 (2): 7-35.

Gunkel, H. (2010) "I myself had a sweetie ...": re-thinking female same-sex intimacy beyond the institution of marriage and identity politics', Social Dynamics 36 (3): 531-46.

Halberstam, J. J. (2012) Gaga Feminism: sex, gender, and the end of normal. Boston MA: Beacon Press.

Hendriks, T. (2018) "“Erotiques cannibales": a queer ontological take on desire from urban Congo', Sexualities 21 (5-6): 853-67.

Hendriks, T. and R. Spronk (2020) 'Introduction' in R. Spronk and T. Hendriks (eds), Readings in Sexualities from Africa. Bloomington IN: Indiana University Press.

Livermon, X. (2012) 'Queer(y)ing freedom: black queer visibilities in postapartheid South Africa', GLQ: A Journal of Lesbian and Gay Studies 18 (2-3): 297-323.

Macharia, K. (2016) 'On being area-studied: a litany of complaint', GLQ: A Journal of Lesbian and Gay Studies 22 (2): 183-90.

Matebeni, Z. (2014) 'How NOT to write about queer South Africa' in Z. Matebeni (ed.), Reclaiming Afrikan: queer perspectives on sexual and gender identities. Athlone: Modjaji Books.

Matebeni, Z. and T. Mbsisi (2015) 'Vocabularies of the non-normative', Agenda 29 (1): 3-9.

Matebeni, Z. and J. Pereira (2014) 'Preface' in Z. Matebeni (ed.), Reclaiming Afrikan: queer perspectives on sexual and gender identities. Athlone: Modjaji Books.

M'Baye, B. (2013) 'The origins of Senegalese homophobia: discourses on homosexuals and transgender people in colonial and postcolonial Senegal', African Studies Review 56 (2): 109-28.

Mohammed, A., C. Nagarajan and R. Aliyu (eds) (2018) She Called Me Woman: Nigeria's queer women speak. Abuja and London: Cassava Republic.

Morgan, R. and S. Wieringa (2005) Tommy Boys, Lesbian Men, and Ancestral Wives: female same-sex practices in Africa. Johannesburg: Jacana Media.

Murray, S. O. and W. Roscoe (eds) (1998) Boy-wives and Female Husbands: studies of African homosexualities. New York NY: St Martin's Press.

Musangi, N. (2014) 'In time and space' in Z. Matebeni (ed.), Reclaiming Afrikan: queer perspectives on sexual and gender identities. Athlone: Modjaji Books.

Nyamnjoh, F. B. (2017) 'Incompleteness: frontier Africa and the currency of conviviality', Journal of Asian and African Studies 52 (3): 253-70. 
Nyanzi, S. (2014) 'Queering queer Africa' in Z. Matabeni (ed.), Reclaiming Afrikan: queer perspectives on sexual and gender identities. Athlone: Modjaji Books.

Nyeck, S. N. (2011) 'Autobiography of things left undone: politics of literature, hyphenation and queered friendship in Africa', Trans-Scripts 1: 172-200.

Nyeck, S. N. (2019) Handbook of African Queer Studies. New York NY: Routledge.

Nyeck, S. N. and M. Epprecht (eds) (2013) Sexual Diversity in Africa: politics, theory, and citizenship. Montreal: McGill-Queen's Press.

Pierce, S. (2016) “Nigeria can do without such perverts": sexual anxiety and political crisis in postcolonial Nigeria', Comparative Studies of South Asia, Africa and the Middle East 36 (1): 3-20.

Reid, G. (2013) How to Be a Real Gay: gay identities in small-town South Africa. Scottsville: University of KwaZulu-Natal Press.

Spronk, R. (2018) 'Invisible desires in Ghana and Kenya: same-sex erotic experiences in cross-sex oriented lives', Sexualities 21 (5-6): 883-98.

Tamale, S. (ed.) (2011) African Sexualities: a reader. Oxford: Pambazuka Press.

van Klinken, A. (2019) Kenyan, Christian, Queer: religion, LGBT activism, and arts of resistance in Africa. New York NY: Pennsylvania State University Press. 